\title{
The pharmacological actions of alcohol in relation to nutrition
}

\author{
By C. W. M. Wirson, Department of Pharmacology, University of Dublin, Trinity \\ College, Dublin 2, Republic of Ireland
}

\begin{abstract}
Introduction
Analysis of the pharmacological action of alcohol in relation to nutrition is difficult in a short paper because ethanol can affect living tissues, and more specifically the human organism, in such a wide variety of ways. Alcohol differs from other pharmacologically active agents in that it is not generally used as a therapeutic substance by the medical profession. Individuals administer alcohol to themselves. Pharmacologically therefore it is desirable to examine the factors which influence its consumption and absorption by these individuals. Social influences are not the sole determining factors for the consumption of alcohol among rats or human beings (Wilson, I969). The sensory perception of alcohol in the mouth is the ultimate physiological factor which determines the quantity of alcohol consumed, its final concentration in the brain and other tissues, and thus its pharmacological actions.

The concentration of alcohol in the blood and tissues is controlled by its metabolism. The production of abnormal metabolites is utilized for therapeutic purposes when drugs are administered to inhibit alcohol dehydrogenase (ADH), the enzyme responsible for production of acetaldehyde from alcohol. The unpleasant sideeffects of acetaldehyde create an aversion to alcohol. Several of these aversive drugs are now available but they do not all act wholly by interfering with the metabolism of alcohol. Some exert their pharmacological action by altering the taste threshold to alcohol or by acting direct on the central nervous system. The relationship of the metabolic and central actions of aversive drugs towards alcohol is an important aspect of the pharmacology of alcohol at the present time.
\end{abstract}

\section{The consumption of alcohol by rats and man}

In most of modern pharmacological experiments on alcohol, rats are allowed to make a choice between alcohol-water mixture and water, which are supplied in separate containers. Under these circumstances rats will drink the alcohol-water mixture selectively, provided its concentration does not exceed about $6 \%(\mathrm{v} / \mathrm{v})$. Above this concentration water is selected in preference to the alcohol-water mixture, though rats continue to consume alcohol-water mixtures in concentrations up to $16 \%(\mathrm{v} / \mathrm{v})$ (Rick \& Wilson, 1969), or higher concentrations (Myers, I962; Mendelson \& Mello, I964; Myers \& Halman, I967). It has been 
shown that daily alcohol consumption remains relatively stable among rats when it is measured in terms of $\mathrm{g} / \mathrm{kg}$ (Wallgren \& Barry, I970).

When the daily consumption of alcohol-water mixture is related to that of pure water, and the concentration of alcohol actually consumed is calculated, it is found that the rats dilute the mixture to a maximum concentration of $3.4 \%(\mathrm{v} / \mathrm{v})$ when they are presented with $8 \%(\mathrm{v} / \mathrm{v})$ alcohol. They dilute $16 \%(\mathrm{v} / \mathrm{v})$ alcohol-water mixture to $3.1 \%(\mathrm{v} / \mathrm{v})$, selectively consuming a larger volume of water from the other container contemporaneously with the mixture (Table I). When given the opportunity to dilute their alcohol, rats, like human beings, will selectively consume an

Table I. Percentage of alcohol consumed by rats when presented with a choice of alcohol-water mixture and water (Modified from Rick $\mathscr{F}$ Wilson, 1969)
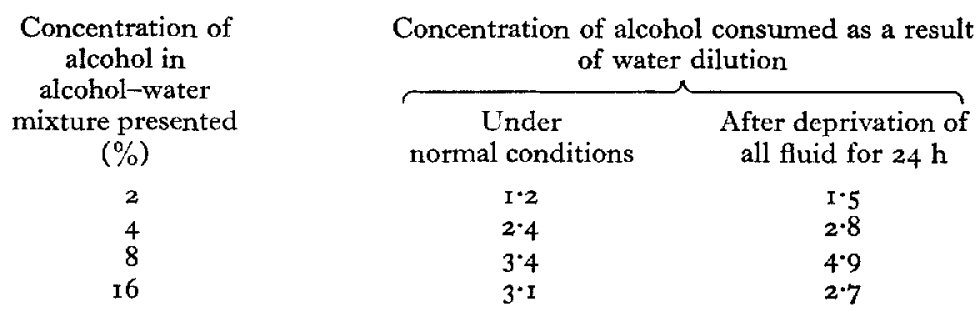

alcohol concentration appropriate to their requirements. In order to do this, they deliberately increase their total fluid consumption of mixture of water according to the state of their fluid balance. The mixture concentration at which they begin to consume a larger volume of pure water than of alcohol-water mixture corresponds to their maximum alcohol preference concentration, that is $5.5-6 \%(\mathrm{v} / \mathrm{v})$ alcohol in the mixture (Fig. I). At this point the highest consumption of alcohol occurs. If rats are offered a mixture above this concentration together with a choice of water, they deliberately dilute the mixture. Above this concentration they develop an aversion to the mixture. They will continue to drink alcohol-water mixtures at higher concentrations. However, the concentration of alcohol which they then consume is lower than that of the mixture at the maximum alcohol preference concentration because they consume a larger quantity of pure water at the same time and a smaller quantity of the more concentrated alcohol in the mixture.

It was assumed by Richter \& Campbell (I940) that rats alter their consumption of alcohol-water mixture and water at the point of the maximum alcohol preference concentration because their taste threshold to alcohol had been exceeded. Although rats continue to consume alcohol at higher mixture concentrations, it has been shown that the quantity of alcohol consumed is not above the metabolic capacity of the rats (Rick \& Wilson, 1966). Since the rats received unlimited food in these experiments, it may be assumed that the alcohol is not being deliberately used as an energy source. It is probably being consumed on account of actions on the central nervous system.

The indirect evidence from experiments with rats showing that consumption of alcohol is controlled by the physiological incentive or disincentive provided by 


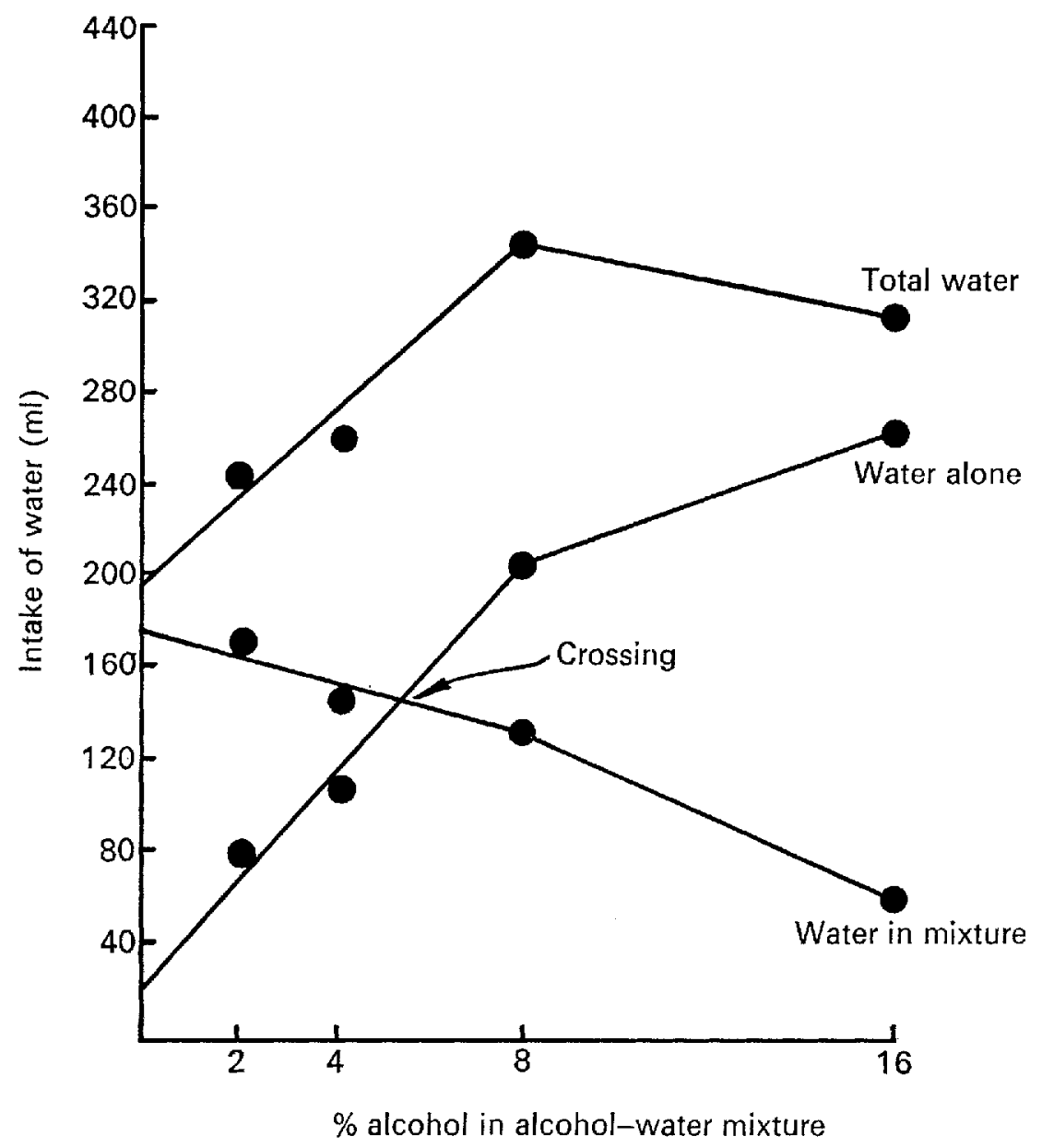

Fig. I. Mean intake of water by groups of six rats when presented with water alone and with $2,4,8$ or $16 \%(\mathrm{v} / \mathrm{v})$ alcohol-water mixtures for $24 \mathrm{~h}$ periods. The contributions of water alone, and of water from the mixture, to the total water consumption are shown for all the groups.

the taste receptors in the mouth has now been confirmed in human beings (Wilson, r969; Wilson, O'Brien, \& MacAirt 1972). Alcohol can first be detected by human beings as a sweet taste at a mean concentration of $4 \cdot 2 \pm 0 \cdot 24 \% \mathrm{SE}(\mathrm{v} / \mathrm{v})$ alcohol in normal young adult subjects. This is defined as the human sweet taste threshold to alcohol. As the concentration of alcohol in the alcohol-water mixture is increased, the sweet taste changes suddenly to a burning taste at a concentration of $2 \mathrm{I} \cdot 2 \pm$ $1.22 \%(\mathrm{v} / \mathrm{v})$ alcohol, and this is defined as the human burning taste threshold to alcohol. At even higher concentrations, the burning taste becomes more intense and finally the subject refuses to accept further concentrations for tasting. These experiments in rats and man confirm that alcohol taste discrimination must be an innate physiological incentive in both. It is the factor which determines the initial choice of alcohol and its continued consumption at higher concentrations. When the aversion taste threshold is exceeded in rats, central mechanisms probably provide 3I (2) 2 
the determining factor for continued consumption. Similar mechanisms may determine the initial selection and continued consumption of alcohol in man (Wilson, 1972a).

\section{Alcohol absorption in man}

The absorption of alcohol from the gastro-intestinal tract is a process of simple diffusion (Berggren \& Goldberg, 1940), Because of the small size and weak charge of the molecule it diffuses easily through cell membranes. The buccal mucosa has been shown to provide a model system representative of the gastro-intestinal tract on which the kinetics of absorption of basic compounds can be investigated (Beckett, Boyes \& Triggs, I 968 ). This model system has been employed to study the kinetics of alcohol absorption. Young human adults were requested to hold concentrations of 4 and $20 \%(\mathrm{v} / \mathrm{v})$ alcohol in their mouths for varying periods (Fig. 2). The smaller concentration fell to half its value within $10 \mathrm{~s}$. The concentration of the $20 \%(\mathrm{v} / \mathrm{v})$ mixture fell to just over $16 \%(\mathrm{v} / \mathrm{v})$ after $10 \mathrm{~s}$ and reached a level of $13 \%(\mathrm{v} / \mathrm{v})$

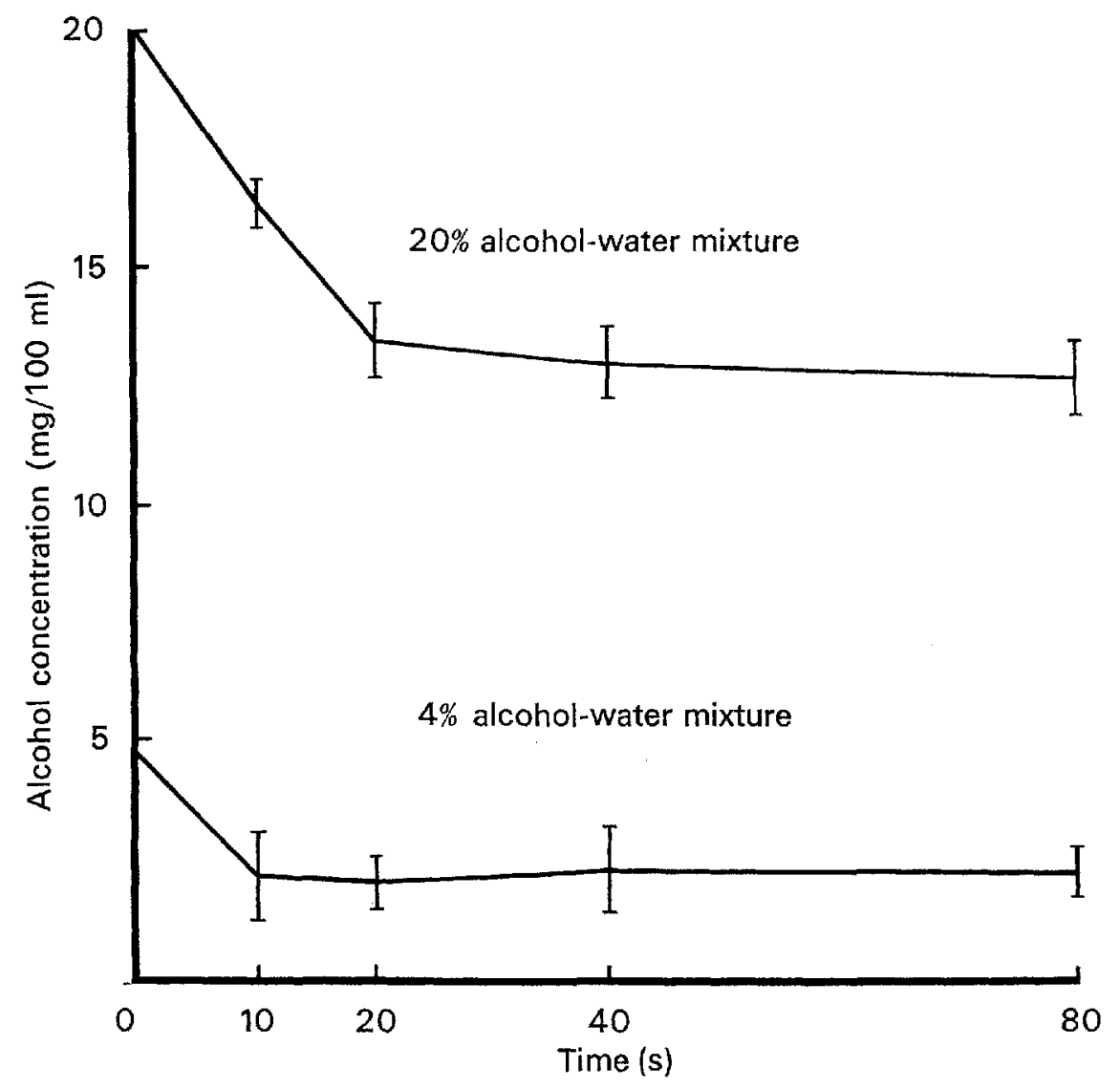

Fig. 2. Reduction in concentration of 20 and $4 \%(\mathrm{v} / \mathrm{v})$ alcohol-water mixtures during their retention in the buccal cavity of young human adults, after introduction of $5 \mathrm{ml}$ of the mixtures into the mouth at zero time. The vertical bars represent the standard deviations of the mean; four subjects per group. 
alcohol after $80 \mathrm{~s}$ in the buccal cavity. Alcohol concentration, in addition to buccal contact time, determines rate of alcohol absorption. Absorption is about twice as fast when the concentration is increased five times.

In relation to the human taste threshold, absorption is slower at the sweet threshold concentration of approximately $4 \%(\mathrm{v} / \mathrm{v})$ alcohol than it is at the burning taste threshold of $20 \%$ (v/v) alcohol. After alcohol administration, its taste threshold in human beings is elevated. Alcohol was administered orally to twelve subjects at 10.00 hours in a dose of $0.8 \mathrm{~g} / \mathrm{kg}$ body-weight. Sweet taste threshold and blood alcohol levels were measured at intervals of $0.5 \mathrm{~h}$ for $2 \mathrm{~h}$. There was a significant rise in the sweet and burning taste thresholds after $0.5 \mathrm{~h}(P<0.01$ for both thresholds $)$ when the blood alcohol concentration had risen to $63.6 \mathrm{mg} / \mathrm{r} 00 \mathrm{ml}$. Miani $8 x$ Vidoni ( 1959 ) administered alcohol in doses of $\mathrm{I}-2 \mathrm{~g} / \mathrm{kg}$ and they found that olfaction was diminished at blood-alcohol concentrations of $40-140 \mathrm{mg} / 100 \mathrm{ml}$. It appears that alcohol reduces the senses of taste and olfaction at much lower concentrations than are required for the impairment of visual or auditory activity (Wallgren \& Barry, 1971).

\section{Interactions between alcohol and other drugs}

Such interactions may occur because other drugs modify the absorption of alcohol by altering gastro-intestinal activity or blood-flow. For example adrenaline, amphetamine and atropine delay the absorption of alcohol in man (Rinkel \& Myerson, 194I; Koda, 1966). The pharmacological action of alcohol may also be modified by drugs which alter its penetration through cell membranes such as the blood-brain barrier by influencing its solubility in lipids (Wallgren, 196r).

Most of the major drug interactions with alcohol occur because of the pharmacological modification of $\mathrm{ADH}$ and other enzymes in the hepatic microsomes which are responsible for the metabolism of alcohol. These enzymes may be the same as those which metabolize barbiturates and numerous other drugs. Induction or inhibition of this system influences the metabolism of alcohol and these other drugs in the same way. Alcohol has been shown to be metabolized more rapidly in chronic alcoholics than in non-drinker controls (Iber, Carulli \& Kater, 1969), probably because of alcoholic induction of the system. The administration of barbiturates to animals before giving them alcohol increases their rate of alcohol elimination (Fischer \& Oelssner, I960; Fischer, 1962; Spector \& Reinhard, I966) because of barbiturate induction of the system. This suggests that when alcoholics have unusually high rates of alcohol elimination, they should have increased capacity to metabolize other drugs. In consequence of these interactions in cell penetration and metabolism outside the nervous system, it is understandable that common actions of alcohol and other drugs may also be modified in the brain. Pronounced modification of the clinical effects of alcohol may appear as a natural consequence of its predominantly central actions. Clinical and experimental evidence indicates that cross tolerance and dependence between alcohol and barbiturates takes place.

Disulfiram and related compounds provide typical examples of drug interaction with alcohol by interference with its catabolism. Disulfiram reduces the 
oxidation of alcohol and acetaldehyde, probably by an inhibitory effect on both the alcohol and aldehyde metabolizing enzymes. The sympathomimetic effects of acetaldehyde are responsible for the disulfiram-alcohol syndrome observed in man when alcohol is consumed during medication with disulfiram. The reaction to alcohol produced after medication with oral hypoglycaemic agents such as tolbutamide and chlorpropamide resembles the disulfiram-alcohol reaction. The clinical effects have been attributed to elevated blood acetaldehyde levels. The hypoglycaemia induced by alcohol enhances the hypoglycaemic actions of chlorpropamide or tolbutamide, and is unresponsive to administration of glucagon or adrenaline, suggesting the occurrence of a state of defective glucose homoeostasis.

Metronidazole causes a voluntary reduction of alcohol intake in rats (Campbell, Taylor \& Haslet, 1967). The evidence that this effect can be attributed to an inhibitory action on $\mathrm{ADH}$ is not convincing; Edwards \& Price (1967) have demonstrated that high concentrations of metronidazole can produce only $50 \%$ inhibition of the enzyme in vitro. The pharmacological action of metronidazole in human beings can be attributed to its effect on the alcohol taste threshold (Wilson, 1970). The administration of $200 \mathrm{mg}$ metronidazole orally four times during I d caused a significant elevation of both the sweet and burning taste thresholds to alcohol (Fig. 3) when concentrations present in the buccal cavity corresponded to those present in the saliva at therapeutic doses. This drug may to a limited extent inhibit the meta-

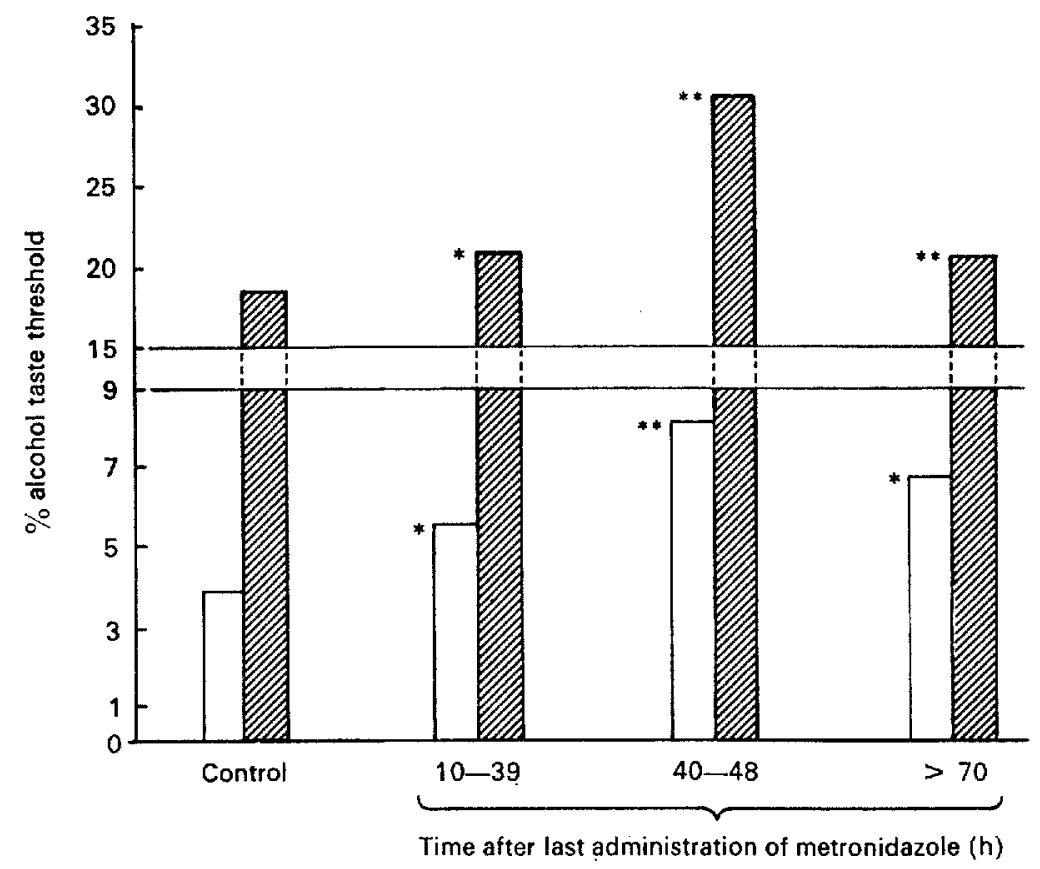

Fig. 3. Effect in human beings of metronidazole on the sweet (plain columns) and burning taste (hatched columns) thresholds to alcohol. Levels of significance of the control taste threshold values compared with the taste thresholds at various times after the last administration of the drug are indicated thus: ${ }^{*} P<0.05$; ${ }^{*} P<0.0 \mathrm{r}$. (Four doses of $200 \mathrm{mg}$ metronidazole were administered orally during the I d after the control thresholds were measured.) (From Wilson, 1969.) 
bolic effect of $\mathrm{ADH}$ on alcohol thus accounting for the very slight features of the disulfiram-alcohol syndrome which have been reported. However, its aversive action arises from its effect primarily on the taste mechanism, and secondarily on the central nervous system. The clinical observation of the occurrence of an unpleasant taste in the mouth due to the appearance of the drug in the saliva supports this conclusion.

Fenfluramine is an appetite depressant. Its mechanism of action has been attributed to production of alterations in fat and carbohydrate metabolism, and also to direct effects on the appetite centre. When fenfluramine was administered to rats, it caused a significant reduction in their intake of 4,6 and $8 \%(\mathrm{v} / \mathrm{v})$ alcoholwater mixtures (Table 2) selectively consumed during six successive $6-\mathrm{d}$ periods.

Table 2. Mean percentage alterations in alcohol concentrations consumed by rats in the groups receiving 4,6 and $8 \%(v / v)$ alcohol-water mixtures after fenfluramine administration at the beginning of period 3 and continuing until the end of period 4 . Each period represents $6 \mathrm{~d}$. a, $20 \mathrm{mg} / \mathrm{kg} ; b, 40 \mathrm{mg} / \mathrm{kg}$ (From Wilson, 1972b)

(a)

Alcohol-water mixture

Period
I and 2
3
4
5
6 $(\%)(\mathrm{v} / \mathrm{v})$

\begin{tabular}{rcc}
4 & 6 & \multicolumn{1}{c}{8} \\
100 & 100 & 100 \\
114 & 101 & 106 \\
83 & 88 & 86 \\
94 & 98 & 112 \\
105 & 105 & 107
\end{tabular}

(b)

Alcohol-water mixture $(\%)(\mathrm{v} / \mathrm{v})$

$\begin{array}{rrr}4 & 6 & 8 \\ 100 & 100 & \text { I00 } \\ 105 & 79 & \text { I I } \\ 83 & 58 & 70 \\ 93 & 84 & \text { I I I } \\ 85 & 75 & \text { I I I }\end{array}$

The rats were given 20 or $40 \mathrm{mg} / \mathrm{kg}$ of fenfluramine during the middle periods (Wilson, I $97^{2} b$ ). The drug had no effect on the consumption of water by the control groups receiving water alone. The group receiving $6 \%(\mathrm{v} / \mathrm{v})$ mixture drank the largest volumes of alcohol which they diluted to $3 \cdot 2 \%(\mathrm{v} / \mathrm{v})$ alcohol by their voluntary water consumption. The dose of $40 \mathrm{mg} / \mathrm{kg}$ of fenfluramine caused the greatest reduction in the concentrations of alcohol consumed. The effect was most pronounced in the rats receiving 4 and $6 \%(\mathrm{v} / \mathrm{v})$ mixtures; they consumed more concentrated alcohol than the group receiving the $8 \%(\mathrm{v} / \mathrm{v})$ mixture on account of the selective water dilution by the latter group. The maximum aversive effect of fenfluramine on alcohol consumption only occurred when a pharmacological balance existed in the rats between the administered dose of fenfluramine and their selected, voluntary consumption of a suitable alcohol-mixture water.

\section{Conclusions}

The endeavours of investigators to produce an experimental model which simulates the human circumstance responsible for generating and perpetuating the effects of intake of alcohol have been unsuccessful until recently because of the difficulty of interpreting the results. The discovery of the human taste threshold to alcohol has confirmed that animal models do provide information about factors which influence human alcohol consumption. The taste thresholds in the two 
species resemble each other in many characteristics, including the occurrence of circadian rhythms, and the similarity of the effects of alcohol dilution (Wilson, 1972a). Humans display their idiosyncrasies with regard to dilution of their drinks while drinking socially. Rats are equally fastidious. It appears that the sensitivity of the taste threshold to alcohol in both species is the determining factor for the selected degree of dilution of alcoholic drinks. Alcohol itself raises the taste threshold. This effect is related to the blood alcohol concentration, but whether it is produced by a direct effect on the taste receptors or through a central action is unknown. In that alcohol is absorbed through the buccal mucosa, it is clear that the effect on the taste receptors could arise by a local pharmacological action.

Any discussion of the pharmacological effects of alcohol must now recognize that the actions both on the brain and through the peripheral sensory receptors have a pronounced influence on its consumption and also determine the effectiveness of various drugs as aversive agents. When these drugs have been absorbed, as with fenfluramine, they affect brain function. This effect can then influence further alcohol intake when the drug itself has been metabolized and excreted.

\section{REFERENCES}

Beckett, A. H., Boyes, R. N. \& Triggs, E. J. (1968). F. Pharm. Pharmac. 20, 92.

Berggren, S. M. \& Goldberg, L. (1940). Acta physiol. scand. I, 246.

Campbell, B., Taylor, J. A. T. \& Haslet, W. L. (1967). Proc. Soc. exp. Biol. Med. 124, I9I.

Edwards, J. A. \& Price, J. (1967). Nature, Lond. 214, 190.

Fischer, H. D. (1962). Biochem. Pharmac. 11, 307.

Fischer, H. D. \& Oelssner, W. (1960). Medna exp. 3,213.

Iber, F. L., Carulli, N. \& Kater, R. M. H. (1969). Fedn Proc. Fedn Am. Socs exp. Biol. $28,626$.

Koda, H. (1966). Fap. F. Stud. Alcohol 1, 2 r2.

Mendelson, J. H. \& Mello, N. K. (1964). Q. Fl Stud. Alcohol 25, I.

Miani, P. \& Vidoni, G. (1959). Clinica otorino.-lar.-iatr. 11, 41 1. (Abstr. in Q. Fl Stud. Alcohol (1962). 23, 338.)

Myers, A. K. (1962). Y. comp. physiol. Psychol. 55, 606.

Myers, R. D. \& Halman, R. B. (1967). Q. Fl Stud. Alcohol z8, 132.

Richter, C. P. \& Campbell, K. H. (1940). Science, N.Y. 9x, 507.

Rick, J. T. \& Wilson, C. W. M. (I966). Q. Il Stud. Alcohol 27, 447.

Rick, J. T. \& Wilson, C. W. M. (I969). Br. F. Addict. Alcohol 64, I5.

Rinkel, M. \& Myerson, A. (1941). F. Pharmac. exp. Ther. 7I, 75.

Spector, E. \& Reinhard, J. F. (1966). American Pharmaceutical Association Meeting, Dallas, Texas. Academy of Pharmaceutical Sciences-Pharmacology and Biochemistry. Abstr. no. 31, p. 66.

Wallgren, H. (1961). Biochem. Pharmac. 6, 195.

Wallgren, H. \& Barry, H. (x97x). Actions of Alcohol Vol. 2, p. 4ro. Amsterdam, London and New York: Elsevier Publishing Co. Ltd.

Wilson, C. W. M. (1969). In The Scientific Basis of Drug Dependence p. 22 I [H. Steinberg, editor]. London: J. \& A. Churchill.

Wilson, C. W. M. (1970). Proc. Nutr. Soc, 29, 29A.

Wilson, C. W. M. (I972a). International Symposium on Biological Aspects of Alcohol Consumption, Helsinki, 1971. (In the Press.)

Wilson, C. W. M. (1972b). International Symposium on Biological Aspects of Alcohol Consumption, Helsinki, I971. (In the Press.)

Wilson, C. W. M., O'Brien, C. \& MacAirt, J. G. (I972). Br. F. Addict. Alcohol (In the Press.) 